\title{
Mental health among young adults in prison: the importance of childhood-onset conduct disorder
}

\author{
Björn Hofvander, Henrik Anckarsäter, Märta Wallinius and Eva Billstedt
}

\section{Background}

The psychiatric health burden of prisoners is substantial. However, there is a lack of high-quality studies of psychiatric disorders among young adults with a high risk of reoffending.

\section{Aims}

To investigate the lifetime prevalence of psychiatric disorders and use of mental health services among young male violent offenders and the impact of childhood-onset conduct disorder (COCD).

\section{Method}

A nationally representative cohort $(n=270$, age 18-25) of male offenders was followed back in medical records and clinically assessed by gold standard methods. Lifetime prevalences are presented together with odds ratios (ORS) as risk estimates in relation to COCD.

\section{Results}

Previous use of psychiatric services among the participants was high but their lifetime psychiatric morbidity was even higher, with 93\% meeting criteria for at least one Axis I disorder. The COCD group was overrepresented in most clinical categories and carried five times higher odds $(\mathrm{OR}=5.1,95 \% \mathrm{Cl} 2.0-12.8)$ of a psychotic disorder, three times higher odds ( $\mathrm{OR}=3.2,95 \% \mathrm{Cl} 1.2-8.5$ ) of a substance use disorder and two times higher odds of a mood disorder $(\mathrm{OR}=2.3,95 \% \mathrm{Cl} 1.3-4.0)$ or anxiety disorder $(\mathrm{OR}=2.0$, $95 \% \mathrm{Cl} 1.1-3.5)$.

\section{Conclusions}

The mental health burden is substantial among young violent offenders, and COCD is an important indicator of future mental health problems which must be a priority for public health efforts.

\section{Declaration of interest}

None.

\section{Copyright and usage}

(c) The Royal College of Psychiatrists 2017. This is an open access article distributed under the terms of the Creative Commons Non-Commercial, No Derivatives (CC BY-NC-ND) license.
The psychiatric health burden of prisoners is substantial, and recent reviews ${ }^{1}$ have established that severe psychiatric disorders, such as psychosis, post-traumatic stress disorder (PTSD) and major depression, are highly overrepresented in general prison populations. However, the prison population is very heterogeneous, and there is mounting evidence of a small number of offenders responsible for a very large share of all serious crimes. ${ }^{2}$ These highrisk individuals are often characterised by an early onset of conduct problems, ${ }^{3,4}$ and we know from follow-up studies that this phenotype carries an increased risk of several other adverse outcomes, such as unemployment, substance abuse and mental illness. ${ }^{5-7}$

The years between the ages of 18 and 25, that is, the 'emerging adulthood', ${ }^{8}$ are a key period for studying the development of serious mental health problems and aggressive antisocial behaviour. These are transitional years, marked by a relative instability in terms of young people's experiences in various salient life domains. ${ }^{9}$ In addition, many authors stress that studies of mental health in prisoners often suffer from methodological problems such as the use of a wide range of screening or self-report tools, ${ }^{10}$ and there is a call for higher quality surveys including information on comorbidity and psychiatric history ${ }^{1}$ as well as the use of clinically trained interviewers to improve the diagnostic validity. ${ }^{11}$ In this article, we have used gold standard methods to produce reliable prevalence figures of psychiatric morbidity among young adults imprisoned for violent offences. A specific aim is to identify systematic differences in previous mental health service use and lifetime psychiatric morbidity between offenders with a childhood onset conduct disorder (COCD) versus those without a history of COCD, that is, a late onset of violent behaviour (LOVB).

\section{Methods}

Despite the many caveats in comparative criminological research, best estimates define Sweden as having a middle-to-high level of violence in terms of common violent crimes such as robbery and assault $^{12}$ in the European context. The Development of Aggressive AntiSocial Behaviour Study (DAABS) is a multicentre study aimed at investigating the prevalence of developmental and clinical disorders in a nationally representative cohort of young adult male violent offenders sentenced to prison. The study will also follow up the participants on criminal recidivism, consumption of physical and psychiatric healthcare and mortality through official Swedish registers.

In Sweden, a small number (approximately 300/year) of primarily violent offenders, suffering from classical psychotic disorders, are court ordered to forensic psychiatric care after going through a forensic psychiatric investigation. These offenders are not included in the DAABS

\section{Participants}

In March 2010, the study began recruiting men aged 18-25 years, convicted of violent or hands-on sexual (i.e. purely internet-based sexual offences were not included) crimes who were imprisoned in any of nine prison facilities in the western region of the Swedish Prison and Probation Service. This region contains prison facilities of all security levels and is approximately equivalent to one-fifth of the whole Swedish Prison and Probation Service.

All participants were required to understand and express themselves in Swedish well enough to participate in the clinical assessments, and to stay at the prison for at least 4 weeks for the assessments to be planned and executed. Participation was compensated with a SEK 200 payment (approximately $£ 17$ ). By 1 July 2012, 379 individuals had met inclusion criteria for the study. Of these, 109 individuals (29\%) declined participation, which yielded a study group of 270 eligible for the study (71\%). Between those who consented and those who declined participation, there was no difference in terms of median age, conviction or country of origin. Two clinical assessments were prematurely ended, because of the 
participants' clinical conditions, and on some variables there was insufficient or opposing information, which resulted in missing data and hence differing totals in the result section.

Sociodemographic and crime-related characteristics of the cohort are reported by Wallinius and colleagues. ${ }^{13}$ There were no significant differences in terms of age, country of origin, educational level or crime characteristics between participants with and without $\mathrm{COCD}$.

\section{Assessments}

Inmates who agreed to participate were consecutively assessed according to a structured protocol, including self-rating questionnaires, semi-structured diagnostic interviews and neuropsychological assessments. The questionnaires were completed by the participants before assessment. All clinical assessments were performed during a full day by one of four licensed psychologists with clinical experience from the field and special training in the instruments used. Before assessment, the psychologist had read all file information, including prison healthcare journals, detailed reports on previous living circumstances and criminal history and incidents during ongoing sanction, available from the Swedish Prison and Probation Service.

\section{Psychosocial background}

Detailed information on ethnicity, schooling, adverse childhood circumstances, institutionalisation during childhood and previous criminality was collected from files and interviews.

\section{Medical history}

A thorough psychiatric history was taken, from files and interviews, covering all previous mental health service contacts including information on care provision, results of assessments, pharmacological and psychological treatments and subjective response to treatment.

\section{Clinical interviews and diagnoses}

Psychiatric assessments were based on the Structured Clinical Interview for DSM-IV Axis I Disorders (SCID-I) ${ }^{14}$ and the SCID-II, ${ }^{15}$ but to assess the disorders not covered in the SCID (e.g. developmental disorders, impulse control disorders and sexual disorders), an amendment including a lifetime DSM-IV ${ }^{16}$ symptom checklist of individual criteria or symptom definitions was added. The Asperger Syndrome Diagnostic Interview $\left(\mathrm{ASDI}^{17}\right)$ was used to assess socio-communicative problems. Further, signs of perceptual and psychomotor aberrations were systematically documented and a basic neurological and neuropsychiatric status was performed. Diagnosis of mental retardation was supported by a psychometric assessment using the General Ability Index subtests ${ }^{18}$ of the Wechsler Adult Intelligence Test - III (WAIS-III ${ }^{19}$ )

Based on all the available information, provided by the files, registers and the clinical interview, the lifetime presence of disorders was assigned according to the DSM-IV ${ }^{16}$ in consensus by the clinical psychologist and one of the principal investigators (E.B or B.H.) according to the LEAD (Longitudinal, Expert, All, Data ${ }^{20}$ ) principle. Because of the high prevalence of polysubstance use in this group, with concomitant difficulties in making reliable decisions on withdrawal symptoms, we decided to collapse the diagnostic categories of abuse and dependence in this study. In accordance with the DSM-IV, COCD was defined as the presence of at least one symptom before the age of 10 among the participants who met the full criteria for conduct disorder.

\section{Data analyses}

Barnard's unconditional exact test ${ }^{21-23}$ was used to compare differences between the subgroups (COCD $v$. LOVB) in terms of sociodemographics, previous psychiatric healthcare consumption and Axis I and II disorders. The choice of Barnard's test was due to it uniformly being more powerful than, for example, Fischer's exact test. Two-sample $t$-tests were used for testing between-group differences on continuous variables. Odds ratios (ORs) with 95\% confidence intervals were calculated and presented as risk estimates in relation to COCD. We defined clinically relevant effects as double or half the prevalence of psychiatric morbidity between the two study groups ${ }^{24}$ measured as an OR of $\geq 2.0$ or $\leq 0.5$, respectively. All statistics were calculated, using anonymised data, with the $\mathrm{R}$ software environment, ${ }^{25}$ using two-tailed $P$-values and a significance threshold of $P \leq 0.05$. Because of the large number of hypothesis tests, the Benjamini-Hochberg method ${ }^{26}$ for controlling the false discovery rate (FDR) was applied to each collection of statistical tests (i.e. for results presented in Tables 1-4). Compared with family-wise error rate control methods, such as the Bonferroni correction, the FDR method has greater power but is at the same time less stringent, which is why it is to be preferred when the risk of type II errors or false negatives should be minimised. All $P$-values are presented in their uncorrected form, with an asterisk indicating that the $P$-value remained significant also after FDR correction.

\section{Ethics}

The study was approved by the regional ethical review board at Lund University (register \#2009/405). All individuals participated voluntarily after giving their written informed consent.

\section{Results}

\section{Previous consumption of psychiatric health services}

As shown in Table 1, 40\% of participants had been in contact with child and adolescent psychiatric services (CAP) and approximately a third (32\%) had previous contacts with adult psychiatric services, both being more common in the COCD group (both $P \leq 0.05$ ). A small minority (4\%) had undergone a forensic psychiatric investigation and $10 \%$ had previously received forensic psychiatric treatment at some point in their lives, though in none of the cases was it court ordered, that is, this care was provided during a prison sentence. There were no differences between the groups on these variables.

In terms of pharmacological treatments, almost a third (28\%) had been treated with an antidepressant with depression as indication, with a tendency of the COCD group to be overrepresented, though the differences did not reach statistical significance $(P=$ 0.098). Mood stabilisers $\left(P=0.002^{\star}\right)$ and particularly valproate $(P \leq 0.038)$ were more common in the COCD group. Antipsychotics $\left(P \leq 0.001^{\star}\right)$, both classical $\left(P=0.002^{\star}\right)$ and quetiapine $\left(P \leq 0.001^{\star}\right)$ were also more common in the COCD group.

\section{Clinical disorders and global functioning}

As shown in Table 2, almost the whole cohort (93\%) met criteria for at least one Axis I disorder in a lifetime perspective. Mood disorders $(54 \%)$ and anxiety disorders (52\%) were the most common clinical categories.

Many of the participants met criteria for substance use disorders (SUDs) $(n=226,84 \%)$ and in most cases they abused multiple substances simultaneously or sequentially ( $72 \%$ had abused two or more substances during their lifetime). A third of the total group (34\%) had used heroin, including smoking heroin, and approximately half of this group (14\%) injected the drug, with no difference between the subgroups $(P=0.548)$. 
Table 1 Previous mental healthcare consumption among prisoners with versus without childhood-onset conduct disorder

\begin{tabular}{|c|c|c|c|c|}
\hline & Total $(n=254-269)$ & $\operatorname{COCD}(n=70-73)$ & LOVB ( $n=183-195)$ & \\
\hline & $n(\%)$ & $n(\%)$ & $n(\%)$ & Comparison, $P^{a}$ \\
\hline Previous CAP contact & $106(40)$ & $36(50)$ & 70 (36) & 0.044 \\
\hline Age at first CAP contact, years; mean (s.d.) & $11.1(3.6)$ & $10.4(3.5)$ & $11.5(3.7)$ & 0.153 \\
\hline Pharmacological treatment at CAP & $28(11)$ & $10(14)$ & $18(9)$ & 0.287 \\
\hline Psychotherapy at CAP & $24(9)$ & $10(14)$ & $14(7)$ & 0.093 \\
\hline Previous adult psychiatric (AP) contact & $86(32)$ & $31(43)$ & $54(28)$ & 0.026 \\
\hline Age at first AP contact, years; mean (s.d.) & $19.2(1.8)$ & $18.8(1.8)$ & $19.5(1.8)$ & 0.098 \\
\hline Compulsory treatment & $8(3)$ & $4(6)$ & $4(2)$ & 0.160 \\
\hline Previous forensic psychiatric investigation & $11(4)$ & $4(6)$ & 7 (4) & 0.560 \\
\hline Treated at forensic psychiatric unit & $27(10)$ & $9(12)$ & $18(9)$ & 0.486 \\
\hline Pharmacological treatment at AP & $51(19)$ & $22(30)$ & $28(15)$ & $0.004^{*}$ \\
\hline Psychotherapy at AP & $26(9)$ & $9(12)$ & $16(8)$ & 0.371 \\
\hline \multicolumn{5}{|l|}{ Previous pharmacological treatment } \\
\hline Any antidepressants, indicated by depression & $75(28)$ & $26(36)$ & $49(25)$ & 0.098 \\
\hline Mood stabilizers, indicated by depression & $16(6)$ & $10(14)$ & $6(3)$ & $0.002^{*}$ \\
\hline Lithium, indicated by mood swings & $0(0)$ & $0(0)$ & $0(0)$ & NA \\
\hline Valproate, indicated by mood swings & $4(2)$ & $3(4)$ & $1(1)$ & 0.038 \\
\hline Lamotrigine, indicated by mood swings & $1(0)$ & $0(0)$ & $1(1)$ & 0.992 \\
\hline Any antipsychotics, any indication & $28(10)$ & $17(23)$ & $11(6)$ & $0.000^{*}$ \\
\hline Depot injections & $0(0)$ & $0(0)$ & $0(0)$ & NA \\
\hline Classical antipsychotics, any indication & $4(2)$ & $4(6)$ & $0(0)$ & $0.002^{*}$ \\
\hline Risperidone, any indication & 7 (3) & $4(6)$ & $3(2)$ & 0.079 \\
\hline Olanzapine, any indication & $13(5)$ & $6(8)$ & 7 (4) & 0.121 \\
\hline Quetiapine, any indication & $9(3)$ & $7(10)$ & $2(1)$ & $0.000^{*}$ \\
\hline Aripiprazole, any indication & $1(0)$ & $1(1)$ & $0(0)$ & 0.119 \\
\hline Any stimulant, indicated by ADHD & $30(11)$ & $10(14)$ & $19(10)$ & 0.404 \\
\hline Atomoxetine indicated by ADHD & $3(1)$ & $0(0)$ & $3(2)$ & 0.325 \\
\hline
\end{tabular}

A total of 21 participants (8\%) met criteria for a psychotic disorder during their lifetime. In most participants these psychotic episodes were assessed as substance induced $(n=20)$ but in a few participants a brief psychotic disorder $(n=1)$ or psychosis not otherwise specified (NOS) $(n=1)$ was diagnosed.

In terms of clinically meaningful effects, participants with COCD had two times higher odds ( $\mathrm{OR}=2.3,95 \%$ CI 1.3-4.0) of a mood disorder, a four times higher odds (OR $=3.7,95 \%$ CI $1.5-$ 9.0) for obsessive-compulsive disorder (OCD), two times higher odds $(\mathrm{OR}=2.4,95 \% \mathrm{CI} 1.4-4.1)$ for abusing substances other than the large substance groups (i.e. those in Table 1 referred to as 'Other substances' including inhalants, anabolic steroids and gamma-hydroxybutyrate), three times higher odds $(\mathrm{OR}=2.7$, 95\% CI 1.3-5.5) for polysubstance abuse and five times higher odds $(\mathrm{OR}=5.1,95 \%$ CI $2.0-12.8)$ of a psychotic disorder. These associations persisted after statistically controlling for FDR.

In addition, there were a number of clinical conditions that were clearly overrepresented among participants with COCD, such as major depressive disorder, bipolar disorders, social phobia, several individual SUDs and dissociative disorder, though these associations did not quite reach statistical significance or were reduced below the significance threshold when we controlled for multiple comparisons.

At the time of the assessment, the total group had a mean Global Assessment of Functioning (GAF) score of 53.0 (s.d. = 9.6). The score was significantly lower, 50.0 (s.d.=9.6), at the time before detention $(P \leq 0.001$, by paired-samples $t$-test). The GAF score of the two groups differed significantly both at the time of the assessment (COCD $\mathrm{M}=48.6$ (s.d.=8.5) v. LOVB $\mathrm{M}=54.7$ (s.d. =9.5), $P \leq 0.001)$ and at the time before detention (COCD $\mathrm{M}=45.9$ (s.d. =7.1) v. $\mathrm{M}=51.5($ s.d. $=10.0)$ ) for the LOVB group $\left(P \leq 0.001^{\star}\right)$.

\section{Personality disorders}

Prevalences and ORs for personality disorders are presented in Table 3. Half of the group $(n=137,51 \%)$ met criteria for an adolescent-onset conduct disorder, and in the whole group $78 \%$ $(n=210)$ were diagnosed with either childhood-onset or an adolescent-onset conduct disorder. COCD was significantly associated with having a personality disorder diagnosis $\left(P \leq 0.001^{\star}\right)$ and the odds were almost seven times higher in this group $(\mathrm{OR}=$ $6.5,95 \%$ CI 2.8-14.9). Among the personality disorders, antisocial $\mathrm{PD}$ stood out as the dominant with almost two-thirds $(N=170$, $63 \%$ ) meeting criteria for this disorder. Here the COCD group had eight times higher odds ( $\mathrm{OR}=8.3,95 \% \mathrm{CI} 3.6-18.9)$. The COCD group was also overrepresented in paranoid personality disorder $(P=0.026)$, but this association did not stand when controlled for FDR. A complex personality constellation, as measured by meeting criteria for two or more personality disorders, was significantly more common in the COCD group $\left(P=0.006^{*}\right)$ and the odds were almost three times higher in this group $(\mathrm{OR}=2.5,95 \% \mathrm{CI}$ $1.3-4.7)$.

\section{Comorbidity}

The comorbidity between different clinical disorders was extensive and $43 \%(n=114)$ met criteria for three or more clinical disorders (Table 2). As seen in Table 4, there was also a marked overlap between different diagnostic categories. Particularly having a history of at least one major depressive episode was related to three different anxiety disorders and psychotic disorders. Psychotic disorders, many of which were substance induced, were related to OCD, substance-induced anxiety and COCD. There were also associations between antisocial personality disorder, OCD, impulse control disorders, SUDs and COCD. COCD was significantly related to psychotic disorders and OCD. 
Table 2 Prevalence of Axis I disorders ${ }^{\text {a }}$ among prisoners with and without childhood-onset conduct disorder

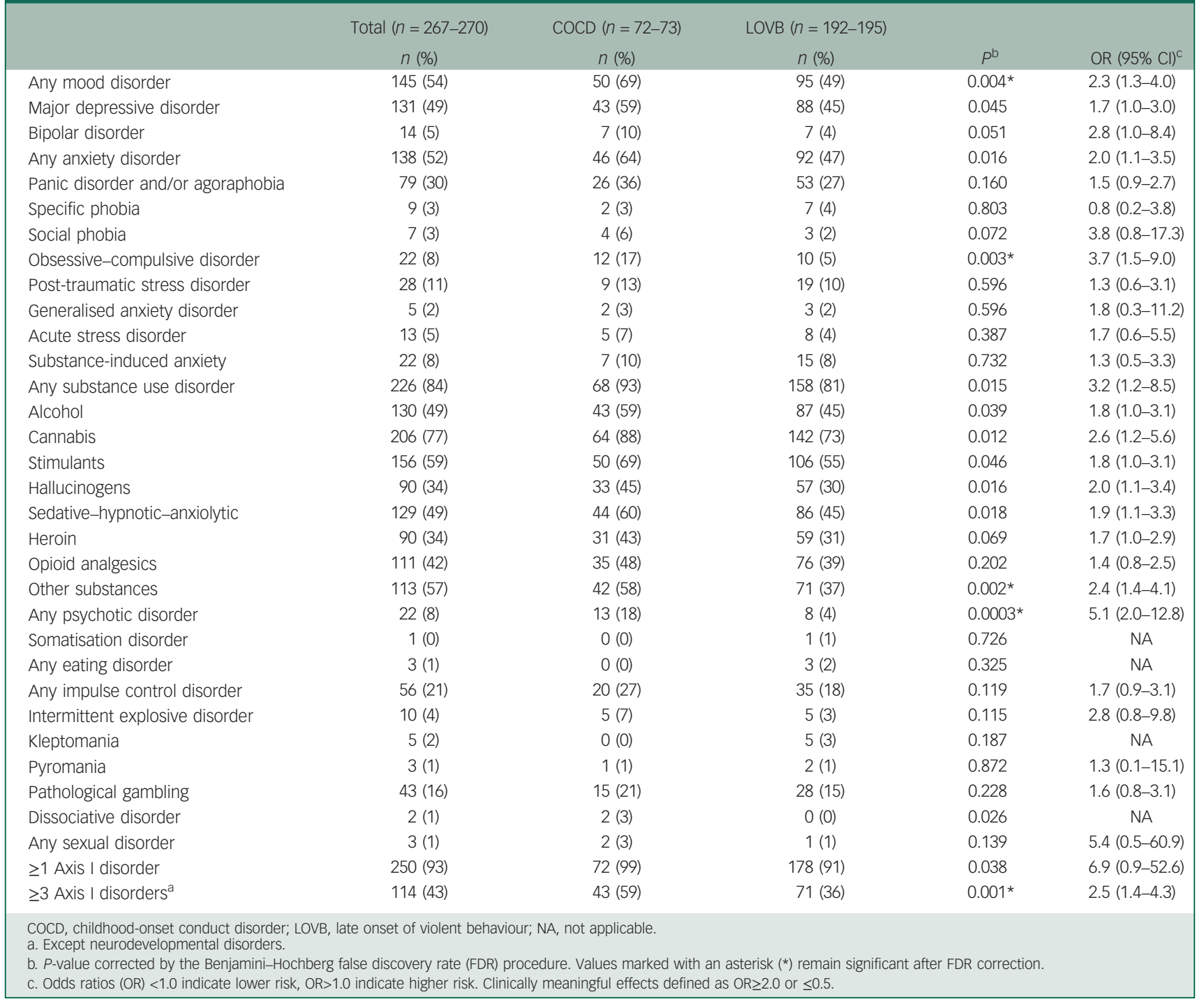

Table 3 Personality disorders among offenders with versus without childhood-onset conduct disorder

\begin{tabular}{|c|c|c|c|c|c|}
\hline & Total $(n=264-268)$ & $\operatorname{COCD}(n=71-73)$ & LOVB $(n=193-195)$ & & \\
\hline & $n(\%)$ & $n(\%)$ & $n(\%)$ & $P^{a}$ & $\mathrm{OR}^{\mathrm{b}}(95 \% \mathrm{Cl})$ \\
\hline Any PD & $177(67)$ & $64(90)$ & $113(59)$ & $0.000 *$ & $6.5(2.8-14.9)$ \\
\hline Paranoid & $26(10)$ & $12(16)$ & $14(7)$ & 0.026 & $2.5(1.1-5.8)$ \\
\hline Schizoid & $0(0)$ & $0(0)$ & $0(0)$ & NA & NA \\
\hline Schizotypal & $0(0)$ & $0(0)$ & $0(0)$ & NA & NA \\
\hline Conduct disorder & $210(78)$ & $73(100)$ & $137(70)$ & $0.000^{*}$ & NA \\
\hline Antisocial & $170(63)$ & $66(90)$ & $104(53)$ & $0.000^{*}$ & $8.3(3.6-18.9)$ \\
\hline Borderline & $13(5)$ & $5(7)$ & $8(4)$ & 0.404 & $1.7(0.5-5.4)$ \\
\hline Histrionic & $0(0)$ & $0(0)$ & $0(0)$ & NA & NA \\
\hline Narcissistic & $0(0)$ & $0(0)$ & $0(0)$ & NA & NA \\
\hline Avoidant & $4(2)$ & $1(1)$ & $3(2)$ & 0.963 & $0.9(0.1-8.7)$ \\
\hline Dependent & $1(0)$ & $0(0)$ & $1(1)$ & 0.727 & NA \\
\hline Obsessive-compulsive & $5(2)$ & $2(3)$ & $3(2)$ & 0.596 & $1.8(0.3-11.0)$ \\
\hline Depressive & $4(2)$ & $0(0)$ & $4(2)$ & 0.259 & NA \\
\hline Passive-aggressive & $6(2)$ & $1(1)$ & $5(3)$ & 0.732 & $0.5(0.1-4.7)$ \\
\hline PD NOS & $19(7)$ & $4(6)$ & $15(8)$ & 0.727 & $0.7(0.2-2.2)$ \\
\hline$\geq 2$ PDS & 49 (19) & $21(30)$ & $28(15)$ & $0.006^{*}$ & $2.5(1.3-4.7)$ \\
\hline
\end{tabular}




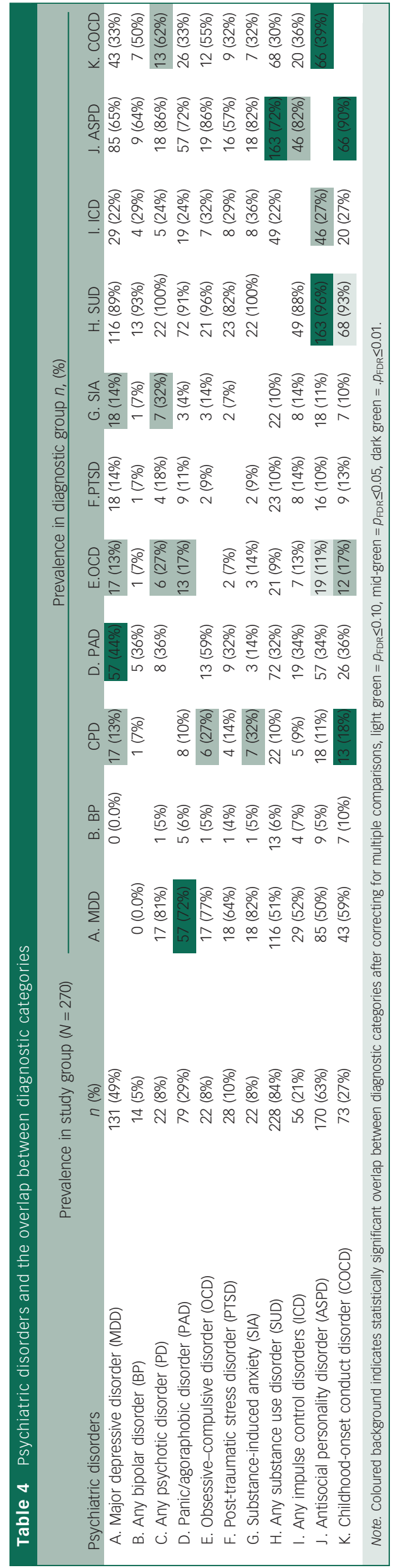

Comorbidity was more common in the COCD group compared with the LOVB group (Table 2) and the odds for having three or more clinical disorders were almost three times higher for the COCD group (OR $=2.5,95 \%$ CI $1.4-4.3)$.

\section{Discussion}

This article reports psychiatric prevalences from a representative cohort of young adult prisoners with a presumed high risk of becoming chronic offenders. In response to limitations in previous studies, we used well-trained clinicians and assessment procedures resembling best practice in general psychiatric healthcare services in our data collection. We also studied the effects of COCD on psychiatric comorbidity and framed the results in the context of clinically important effects, defined as an OR of more than 2.0 or less than 0.5 , i.e. a double or half risk of comorbidity between the two study groups. This approach allowed us to conclude that there were several clinically relevant differences.

\section{Overall psychiatric morbidity}

This article confirms the important finding from previous studies that young male prisoners sentenced for violent crimes carry a highly disproportionate burden of psychiatric disorders. Excluding neurodevelopmental disorders, only 18 of the 270 young men sentenced for violent crimes never met criteria for a psychiatric diagnosis. This is twice as much as the highest rate previously found (47\%) in national and cross-national household surveys. ${ }^{27,28}$ However, it is more in agreement with previous research on offender groups, where lifetime prevalence rates of psychiatric disorders of between 57 and $84 \%$ have been reported. ${ }^{29,30} \mathrm{~A}$ previous review on the epidemiology of psychiatric disorders among prisoners has emphasised very high rates of comorbidity of psychiatric disorders, especially psychiatric disorders in combination with substance-related disorders. ${ }^{31}$ Fazel and colleagues ${ }^{11}$ concluded that the risk increase for psychotic illnesses among adolescents in juvenile detention and correctional facilities was about ten times, which is in line with the present results. Other serious psychiatric disorders, such as bipolar disorder and PTSD, were also clearly overrepresented.

However, no previous research has reported prevalence rates as high as those found in the present study, which might be because of the methods applied (extensive clinical assessments by clinically experienced psychologists) and the study of lifetime prevalence instead of current state only, as well as this study including only violent offenders in emerging adulthood, as late adolescence and young adulthood have been portrayed as the periods with the highest risk of developing psychiatric disorders. ${ }^{32,33}$ When considering the high prevalence rates of psychiatric disorders in this study, it must also be kept in mind that this is a specific cohort that also shows a considerable amount of childhood adversity, ${ }^{13}$ something that is known to be associated with a higher risk for developing psychopathology. ${ }^{34}$

Many of these participants come from deprived backgrounds with less access to and use of healthcare in the community. Although many of the participants had been in contact with the CAP services, there are reasons to suspect that the treatments and interventions provided previously were insufficient or inadequate. Within CAP services, there is still a strong focus on the familial and social correlates of mental health issues. The diagnostic culture, at least outside the neurodevelopmental realm, is still restrained and interventions are often cautious. In services for young, as well as adult, patients, disruptive behaviours and substance abuse often shield comorbidity such as mood or anxiety disorders from clinicians' attention. The present findings of 
approximately $30 \%$ of the young adult violent offenders having been in contact with adult psychiatric services should be seen in the context of the much higher actual prevalence (approximately $70-80 \%)$ of psychiatric disorders requiring referrals to secondary mental healthcare providers. That is, the mental healthcare needs of young violent offenders have not been adequately met by society.

\section{The importance of COCD}

To explore the possibility that conduct problems in childhood may have resulted in developmental 'snares', ${ }^{35}$ making this group especially prone to developing symptoms of psychiatric disorders, we compared the group with an early onset of conduct disorder with those with a later onset of violent behaviour.

In this study, which is one of the first to address these issues, we have been able to show that within a prison setting, the subgroup with an early onset of serious conduct problems represents a particularly vulnerable group. There was an increased risk of all large categories of psychiatric disorders in the COCD group, in line with previous findings from, for example, Fergusson and colleagues, ${ }^{5}$ Moffitt $^{36}$ and Kretschmer and colleagues. ${ }^{37}$ Despite increased prevalence of CAP contacts during childhood, we did not find a difference regarding age at first psychiatric contact or level of treatment at this stage. However, the COCD group consumed more psychiatric care and significantly more pharmacological treatment, including antipsychotics, as adults. These findings could reflect the fact that these children often lack support from family members and that community representatives, for example, in school, often explain their behaviour solely as a result of their social situation. There is reason to argue that these children could be identified and treated at an earlier age. These findings have important implications for social welfare institutions, the school system and all healthcare providers.

\section{Limitations}

There are several limitations to this study. First, it has a retrospective design, which might interfere with the reliability of historical data. However, to allow neurodevelopmental and lifetime mental health perspectives on relatively large samples of rare phenotypes such as these, possibly persistent, violent offenders, this design is one of few available. The choice of young adults gives the benefits, apart from the study of an important developmental period per se, of participants whose age is high enough for them to conceive their own medical history and low enough for them to remember a fair amount of their background. Data collection also included file information such as medical registers and all other available documents. For all participants we also asked permission to contact their parents, caregivers or others who knew them as children. However, in many cases we were unable to reach these people. There are reasons to believe that oppositional defiant disorder (ODD) plays an important part in the heterotypical pattern of psychiatric disorders in this group. ${ }^{38}$ However, the SCID-I and II do not cover ODD and in the DSM-IV, ODD is ruled out if criteria for conduct disorder are met.

Finally, we have not been able to establish inter-rater reliability for the assessments. However, the same expert instructors have educated the clinicians, most often simultaneously, with several training sessions focusing on agreement between assessments. Diagnostic decisions were also made in consensus by the clinicians and the principal investigators.

\section{Implications}

The results of this study emphasise the need to improve prison medical services to increase the ability to assess and treat the large burden of psychiatric disorders among prisoners. Prisons provide a rare public health opportunity to screen and intervene in a young, marginalised and highly exposed group. A recent, longitudinal cohort study on nearly 50000 prisoners $^{39}$ showed that treatable psychiatric disorders were related to reoffending and that the risk of reoffending increased with the number of diagnosed disorders. In young adult male offenders, the 3-year recidivism rates are about $50 \%{ }^{40}$ This makes it urgent to review the provision of mental healthcare in prison settings to counteract this cycle of reoffending. There are also strong reasons to specifically address individuals with an early onset of conduct problems, because a persistent pattern of antisocial behaviour in young children is an important precursor to future mental health problems and severe criminality. We need to improve our methods to identify and provide evidence-based interventions for these children.

\footnotetext{
Björn Hofvander, PhD, Department of Clinical Sciences, Lund, Child and Adolescent Björn Hofvander, PhD, Department of Clinical Sciences, Lund, Child and Adolescent
Psychiatry, Faculty of Medicine, Lund University, Lund, Sweden; Division of Forensic Psychiatry, Region Skåne, Kristianstad, Sweden; Department of Psychiatry, Autism Research Centre, University of Cambridge, Cambridge, UK; Henrik Anckarsäter, MD, Department of Forensic Psychiatry, Centre of Ethics, Law and Mental Health, Institute of Neuroscience and Physiology, University of Gothenburg, Gothenburg, Sweden; Märta Wallinius, PhD, Department of Clinical Sciences, Lund, Child and Adolescent Psychiatry, Faculty of Medicine, Lund University, Lund, Sweden; Regional Forensic Psychiatric Clinic, Växjö, Sweden; Eva Billstedt, PhD, Gillberg Neuropsychiatry Centre, Institute of Neuroscience and Physiology, Sahlgrenska Academy at the University of Gothenburg, Gothenburg, Sweden

Correspondence: Björn Hofvander, Division of Forensic Psychiatry, Sege Park B6, plan 2, SE-20502 Malmö, Sweden. Tel: +46 403356 23. Email: bjorn.hofvander@med.lu.se
}

First received 6 Sep 2016, final revision 12 Dec 2016, accepted 28 Feb 2017

\section{Acknowledgements}

The authors thank Lennart Palmgren and Svenolov Svensson for their generous support of the study, all site managers for their hard work during the assessments, Therese Olsson, Natalia Theander and Mattias Filipazzi for indispensable help during data collection and Monika Montell, Jan Wikdahl and Stefan Axelsson for their help with the database. We also thank Carl Delfin for his statistical advice. Finally we would like to express our gratitude to all participants and their families for their participation.

\section{Funding}

The study was supported by grants from the Swedish Prison and Probations Services, Region Skåne, Region Kronoberg, Södra sjukvårdsregionen, Stiftelsen Lindhaga and government grants under the ALF agreement.

\section{References}

1 Fazel S, Seewald K. Severe mental illness in 33588 prisoners worldwide: systematic review and meta-regression analysis. Br J Psychiatry 2012; 200: 364-73.

2 Falk $\mathrm{O}$, Wallinius $\mathrm{M}$, Lundström $\mathrm{S}$, Frisell $\mathrm{T}$, Anckarsäter $\mathrm{H}$, Kerekes $\mathrm{N}$. The $1 \%$ of the population accountable for $63 \%$ of all violent crime convictions. SOC Psychiatry Psychiatr Epidemiol 2014; 49: 559-71.

3 Gelhorn HL, Sakai JT, Price RK, Crowley TJ. DSM-IV conduct disorder criteria as predictors of antisocial personality disorder. Compr Psychiatry 2007; 48: 529-38.

4 Hofvander B, Ossowski D, Lundström S, Anckarsäter H. Continuity of aggressive antisocial behavior from childhood to adulthood: the question of phenotype definition. Int J Law Psychiatry 2009; 32: 224-34.

5 Fergusson DM, Boden JM, Horwood L. Childhood self-control and adult outcomes: results from a 30-year longitudinal study. J Am Acad Child Adolesc Psychiatry 2013; 52: 709-17.

6 Kim-Cohen J, Caspi A, Moffit TE, Harrington HL, Milne BJ, Poulton R. Prior juvenile diagnoses in adults with mental disorder: developmental follow-back of a prospective-longitudinal cohort. Arch Gen Psychiatry 2003; 60: 709-17.

7 Morcillo C, Duarte CS, Sala R, Wang S, Lejuez CW, Kerridge BT, et al. Conduct disorder and adult psychiatric diagnoses: associations and gender differences in the U.S. adult population. J Psychiatr Res 2012; 46: 323-30.

8 Arnett JJ. Emerging adulthood: a theory of development from the late teens through the twenties. Am Psychol 2000; 55: 469-80. 
9 McAdams DP, Olson BD. Personality development: continuity and change ove the life course. Annu Rev Psychol 2010; 61: 517-42.

10 Martin MS, Colman I, Simpson Al, McKenzie K. Mental health screening tools in correctional institutions: a systematic review. BMC Psychiatry 2013; 29: 275.

11 Fazel S, Doll H, Långström N. Mental disorders among adolescents in juvenile detention and correctional facilities: a systematic review and metaregression analysis of 25 surveys. J Am Acad Child Adolesc Psychiatry 2008; 47 1010-9.

12 Van Dijk J, Van Kesteren J, Smit P, Tilburg University, UNICRI, UNODC. Crimina Victimisation in International Perspective: Key Findings from the 2004-2005 ICVS and EU ICS. Ministry of Justice, WODC, 2007.

13 Wallinius $M$, Delfin $C$, Billstedt $E$, Nilsson $T$, Anckarsäter $H$, Hofvander $B$. Offenders in emerging adulthood: school maladjustment, childhood adversities and prediction of aggressive antisocial behaviors. Law Hum Behav 2016; 40 551-63.

14 First MB. Structured Clinical Interview for DSM-IV Axis I Disorders: SCID-I: Clinician Version: Administration Booklet. American Psychiatric Press, 1997.

15 First MB. User's Guide for the Structured Clinical Interview for DSM-IV Axis II Personality Disorders: SCID-II. American Psychiatric Press, 1997.

16 American Psychiatric Association. Diagnostic and Statistical Manual of Mental Disorders, Fourth Edition: DSM-IV-TRß. APA, 2000.

17 Gillberg C, Gillberg IC, Råstam M, Wentz E. The Asperger Syndrome (and highfunctioning autism) Diagnostic Interview (ASDI): a preliminary study of a new structured clinical interview. Autism 2001; 5: 57-66.

18 Tulsky DS, Saklofske DH, Wilkins C, Weiss LG. Development of a general ability index for the Wechsler Adult Intelligence Scale - Third Edition. Psychol Assess 2001; 13: 566-71.

19 Wechsler D. Wechsler Adult Intelligence Scale - Third Edition. The Psychological Corporation, 1997.

20 Spitzer RL. Psychiatric diagnosis: are clinicians still necessary? Compr Psychiatry 1983; 24: 399-411.

21 Barnard GA. A new test for $2 \times 2$ tables. Nature 1945; 156: 177

22 Barnard GA. Significance tests for 2 × 2 tables. Biometrika 1947; 34: 123-38.

23 Lydersen S, Fagerland MW, Laake P. Recommended tests for association in $2 \times 2$ tables. Stat Med 2009; 28: 1159-75.

24 Last JM. A Dictionary of Epidemiology, 4th edn. Oxford University Press, 2001.

25 R Core Team. R: A Language and Environment for Statistical Computing. R Foundation for Statistical Computing, 2014 (http://www.R-project.org/).

26 Benjamini $Y$, Hochberg $Y$. Controlling the false discovery rate: a practical and powerful approach to multiple testing. J Roy Stat SoC B 1995; 57: 289-300.

27 Kessler RC, Berglund $\mathrm{P}$, Demler $\mathrm{O}$, Jin R, Merikangas KR, Walters EE. Lifetime prevalence and age-of-onset distributions of DSM-IV disorders in the National Comorbidity Survey Replication. Arch Gen Psychiatry 2005; 62 593-602.
28 Kessler RC, Angermeyer M, Anthony JC, DE Graaf R, Demyttenaere K, Gasquet et al. Lifetime prevalence and age-of-onset distributions of mental disorders in the World Health Organization's World Mental Health Survey Initiative. World Psychiatry 2007; 6: 168-76.

29 Longato-Stadler E, Von Knorring L, Hallman J. Mental and personality disorders as well as personality traits in a Swedish male criminal population. Nord J Psychiatry 2002; 56: 137-44.

30 Vicens E, Tort V, Dueñas RM, Muro Á, Pérez-Arnau F, Arroyo JM, et al. The prevalence of mental disorders in Spanish prisons. Crim Behav Ment Health 2011; 21: 321-32.

31 Sirdifield C, Gojkovic D, Brooker C, Ferriter M. A systematic review of research on the epidemiology of mental health disorders in prison populations: a summary of findings. J Forens Psychiatry Psychol 2009; 20: 78-101.

32 Burke KC, Burke JD Jr, Regier DA, Rae DS. Age at onset of selected mental disorders in five community populations. Arch Gen Psychiatry 1990; 47: 511-8.

33 Newman DL, Moffitt TE, Caspi A, Magdol L, Silva PA, Stanton WR. Psychiatric disorder in a birth cohort of young adults: prevalence, comorbidity, clinical significance, and new case incidence from ages 11 to 21. I Consult Clin Psychol 1996; 64: 552-62.

34 Kessler RC, McLaughlin KA, Green JG, Gruber MJ, Sampson NA, Zaslavsky AM, et al. Childhood adversities and adult psychopathology in the WHO World Mental Health Surveys. Br J Psychiatry 2010; 197: 378-85.

35 Moffitt TE. Adolescence-limited and life-course-persistent antisocial behavior: a developmental taxonomy. Psychol Rev 1993; 100: 674-701.

36 Moffitt TE. Life-course persistent versus adolescence-limited antisocial behavior. In Developmental Psychopathology (eds D Cicchetti, DJ Cohen): 2nd edn, Vol. 3 pp. 570-98. Wiley, 2006

37 Kretschmer $\mathrm{T}$, Hickman $\mathrm{M}$, Doerner $\mathrm{R}$, Emond $\mathrm{A}$, Lewis $\mathrm{G}$, Macleod et al. Outcomes of childhood conduct problem trajectories in early adulthood: findings from the ALSPAC study. Eur Child Adolesc Psychiatry 2014; 23: 539-49.

38 Copeland WE, Shanahan L, Costello EJ, Angold A. Childhood and adolescent psychiatric disorders as predictors of young adult disorders. Arch Gen Psychiatry 2009; 66: 764-72

39 Chang Z, Larsson $\mathrm{H}$, Lichtenstein $\mathrm{P}$, Fazel S. Psychiatric disorders and violent reoffending: a national cohort study of convicted prisoners in Sweden. Lancet Psychiatry 2015; 2: 891-900.

40 Brottsförebyggande rådet (Brå). Crime Statistics, Recidivism, Recidivism among All Men by Age 2004-2008 (http://www.bra.se/bra/bra-in-english/home/crimeand-statistics/crime-statistics.html). 